\title{
Preparação e Avaliação de Célula a Combustível do Tipo PaCOS Unitária com Ânodo a base de Níquel e Cobalto
}

Marcos Aurélio da Silva, Marcelo Gonçalves F. de Alencar, Raigenis P. Fiúza, Jaime S. Boaventura

GECIM - Grupo de Energia e Ciência dos Materiais

Instituto de Química, UFBA, Campus Universitário de Ondina, 40190-270 Salvador-BA

e-mail: marcosas@ufba.br, marceloxyz@gmail.com, raigenis@ufba.br, bventura@ufba.br.

\begin{abstract}
RESUMO
Uma célula a combustível do tipo PACOS unitária foi preparada e avaliada na geração de energia elétrica, utilizando metano ou hidrogênio como combustível. O ânodo da célula foi sintetizado a partir do eletro-catalisador desenvolvido e testado nesse trabalho (CATAC). O CATAC foi preparado pela mistura mecânica da zircônia estabilizada com ítria (YSZ) com os precursores metálicos (nitrato de níquel e cobalto, em sua forma hexahidratado), adicionando-se $25 \%$ de ácido cítrico à massa total da mistura e por fim calcinado a $800^{\circ} \mathrm{C}$ por quatro horas em ar. O catalisador foi caracterizado por fluorescência de raios $\mathrm{X}$ (XRF) e espectroscopia foto-eletrônica de raios X (XPS), a qual não indicou interação eletrônica entre o cobalto e níquel; o teor metálico do CATAC foi de aproximadamente $35 \%$ em massa. O CATAC foi testado para a geração de hidrogênio a partir da reforma a vapor do metano, mostrando boa produtividade de hidrogênio a partir de $600^{\circ} \mathrm{C}$. A estrutura do ânodo/eletrólito/cátodo foi preparada por prensagem de uma camada de CATAC misturado com grafite, uma camada de YSZ puro, e uma camada de óxido misto de lantânio, estrôncio e manganês (LSM) e grafite. $\mathrm{O}$ conjunto foi então prensado e sinterizado a $1380^{\circ} \mathrm{C}$ por quatro horas. Nas superfícies do ânodo e cátodo foram fixadas telas de platina, com o auxílio de tinta de platina, sendo o conjunto aquecido a $1100^{\circ} \mathrm{C}$. Todo o sistema foi colado a um reator de alumina utilizando cola cerâmica. Microscopias por MEV da estrutura mostraram eletrólito denso e eletrodos porosos, com um conjunto adequadamente sinterizado. A célula unitária foi testada utilizando metano ou hidrogênio como combustível, a três temperaturas de operação. A tensão variou inversamente proporcional com a corrente, quando o desempenho foi medido a 850 ou $950^{\circ} \mathrm{C}$ e hidrogênio, mas manteve-se constante acima de cinco $\mathrm{mV}$ a $800^{\circ} \mathrm{C}$ com metano. A célula unitária mostrou um desempenho satisfatório na geração de eletricidade tanto com metano quanto com hidrogênio como combustíveis.
\end{abstract}

Palavras chaves: Rede Cooperativa, pilha a combustível, óxido sólido, catalisador, níquel, cobalto, YSZ.

\section{Synthesis and Evaluation of Solid Oxide Fuel Cell (SOFC) with Anode based on Nickel and Cobalt}

\section{ABSTRACT}

A unitary solid oxide fuel cell (SOFC) was prepared and evaluated for the electric energy generation, using methane and hydrogen as fuel. The cell anode was made with the electro-catalyst developed and characterized in this work (CATAC). CATAC was prepared by the mechanical mixture of zirconia stabilized with ytria (YSZ) and the metallic precursors (nickel and cobalt nitrate, hexahydrated), adding $25 \%$ of citric acid to the total mass, and finally calcined at $800^{\circ} \mathrm{C}$ for four hours in air. The catalyst was characterized by X-ray fluorescence (XRF) and X-ray photo-electronic spectroscopy (XPS), which did not indicate any electronic interaction between nickel and cobalt; CATAC metal content was approximately $35 \%$ in mass. CATAC was tested for the hydrogen generation from methane vapor reforming, showing good productivity starting at $600^{\circ} \mathrm{C}$. The anode/electrolyte/cathode structure was prepared by pressing a layer of CATAC mixed with graphite, a pure YSZ layer, and a layer of lanthanum, strontium and manganese mixed oxide (LSM) and graphite. The set was then pressed and sintered at $1380^{\circ} \mathrm{C}$ for four hours. Platinum screens were fixed, with the aid of platinum ink, on the anode and cathode surfaces; the structure was heated to $1100^{\circ} \mathrm{C}$. The system was glued to an alumina reactor using high temperature ceramic bond. SEM micrographs of the anode/electrolyte/cathode structure showed porous electrode and dense electrolyte, in a well sintered ceramic set. The unitary SOFC was tested using methane or hydrogen as fuel, at three different temperatures. The tension varied inversely proportional with the current, when measured at 850 or $950^{\circ} \mathrm{C}$ and 
hydrogen, but the tension was constant above five $\mathrm{mV}$ at $800^{\circ} \mathrm{C}$, with methane. The unitary cell showed a satisfactory performance for electricity generation with both methane and hydrogen as combustible.

Keywords: Cooperative net, fuel cell, solid oxide, catalyst, nickel, cobalt, YSZ.

\section{INTRODUÇÃO}

A pilha ou célula a combustível é um dispositivo eletroquímico que transforma continuamente a energia química em energia elétrica. O combustível é geralmente o hidrogênio ou um composto que o contenha; o oxidante é o oxigênio atmosférico. O hidrogênio utilizado no processo pode ser obtido de várias fontes, por exemplo, eletrólise da água, mas principalmente da reforma do gás natural, ou derivados do petróleo. A reforma do etanol tem um interesse especial, devido aos aspectos ambientais. A célula a combustível é constituída por dois elétrodos (ânodo e cátodo), separados por um eletrólito. O eletrólito funciona como condutor iônico e separa o combustível do oxidante. Os elétrodos são ligados eletricamente por um circuito externo, o qual alimenta o consumidor de energia. As células a combustível têm a vantagem de ser altamente eficientes e pouco poluentes. As aplicações mais importantes para as pilhas a combustível são as centrais de produção de eletricidade, principalmente na forma distribuída, veículos elétricos motorizados e equipamentos elétricos portáteis $[\underline{1}, \underline{2}]$.

Dentre os vários tipos, a pilha a combustível de óxido sólido (PACOS) tem despertado especial interesse, devido à sua alta flexibilidade de combustíveis, uso de materiais não nobres, resistência à contaminantes, alta eficiência e possibilidade de projeto em ampla faixa de potências (desde miliwatts a megawatts). As PACOS funcionam na faixa de temperaturas de 600 a $1000^{\circ} \mathrm{C}$, possibilitando assim alta taxa das reações, tanto química como eletroquímica, sem a utilização de catalisadores nobres [2]. Devido às altas temperaturas de operação, o combustível pode ser reformado diretamente no ânodo, não sendo necessária a utilização de uma unidade de reforma externa. Além disso, a PACOS oferece a possibilidade de co-geração com sistema de turbina a gás, alcançando eficiências acima de $70 \%$. No entanto, os materiais cerâmicos que constituem estas células acarretam dificuldades adicionais na sua utilização, envolvendo custos de fabricação elevados e vários equipamentos adicionais para que a célula produza energia elétrica. Esse sistema extra engloba o pré-aquecimento do combustível e do ar, o sistema de refrigeração, entre outros [ $\underline{3}-\underline{5}]$. A célula unitária do tipo PACOS consiste essencialmente de dois eletrodos porosos separados por um eletrólito denso, condutor de íons oxigênio $\left(\mathrm{O}^{2-}\right)$. O eletrólito utilizado neste tipo de célula é um óxido metálico sólido e não poroso, usualmente o YSZ. Tipicamente o ânodo é formado por um eletro-catalisador de metal suportado e o cátodo é formado pelo LSM, um óxido misto de lantânio, estrôncio e manganês $\left(\mathrm{Sr}-\mathrm{LaMnO}_{3}\right)$. Tanto o cátodo quanto o ânodo devem ter uma elevada porosidade para permitir uma adequada permeação do combustível e do oxigênio. Uma característica fundamental do eletro-catalisador é que deve possuir um elevado teor metálico, acima de $35 \%$, para permitir uma boa condutividade elétrica [6].

Os eletro-catalisadores a base de níquel e cobalto suportados em YSZ têm despertado muito interesse como ânodo para pilhas a combatível de alta temperatura, alimentadas a etanol. Esses eletrocatalisadores apresentam elevada atividade para produção de hidrogênio e resistência à formação de coque [7]. Na produção do ânodo utiliza-se um cermet de Ni/YSZ, Co/YSZ ou Ni-Co/YSZ []]. O cermet poroso de $\mathrm{Ni} / Y S Z$ é o material o mais comum do ânodo para aplicações em PACOS por causa de seu custo baixo, sua boa estabilidade química a altas temperaturas e por apresentar coeficiente de expansão térmica próximo ao YSZ. Outra característica importante é a baixa resistência intrínseca à transferência de carga, associada à atividade eletrocatalítica na fronteira Ni/YSZ. Na estrutura do ânodo, pelo menos $20 \%$ de porosidade é requerida para facilitar o transporte de reagentes e produtos. O níquel atua como um excelente catalisador de reforma e como eletro-catalisador para a oxidação eletroquímica do hidrogênio; enquanto o YSZ constitui uma estrutura para a dispersão das partículas de níquel e inibe a sua coalescência durante a operação da pilha. Além disto, o coeficiente de expansão térmica do ânodo pode ser controlado combinando-se o YSZ e o níquel com outros componentes, misturando-se esses produtos na proporção desejada [9-11].

Este trabalho apresenta os resultados de preparação de um cermet níquel-cobalto suportado em YSZ. Esse cermet foi testado como catalisador para a reforma a vapor do metano, sendo caracterizado por XRF e XPS. Além disto, esse material foi utilizado na preparação do ânodo de uma célula do tipo PaCOS unitária, a qual teve seu desempenho avaliado com hidrogênio e metano $[\underline{12}, \underline{13}]$. 


\subsection{Preparação do Eletro-catalisador}

O eletro-catalisador CATAC foi preparado misturando-se mecanicamente os precursores metálicos, nitrato de cobalto hexahidratado $\left[\mathrm{Co}\left(\mathrm{NO}_{3}\right)_{2} \cdot 6 \mathrm{H}_{2} \mathrm{O}\right]$ com nitrato de níquel hexahidratado $\left[\mathrm{Ni}\left(\mathrm{NO}_{3}\right)_{2} \cdot 6 \mathrm{H}_{2} \mathrm{O}\right.$ ], ambos da marca MERCK, com o suporte YSZ ( $8 \%$ molar de $\mathrm{Y}_{2} \mathrm{O}_{3}$ em $\mathrm{ZrO}_{2}$ ) [NexTech]. Foram também adicionados $25 \%$ de ácido cítrico [MERCK] à massa total dos sólidos precursores e posteriormente uma pequena quantidade de água deionizada para melhor homogeneização da mistura sólida. Em seguida o eletrocatalisador foi calcinado a $800^{\circ} \mathrm{C}$ por quatro horas na presença de ar. As massas do suporte e dos precursores metálicos foram calculadas para que a composição química do eletro-catalisador fosse aproximadamente $32 \%$ em níquel e $3 \%$ em cobalto, ambas as percentagens em massa, considerando-se a forma metálica. Uma amostra de eletro-catalisador similar ao CATAC foi caracterizada por espectrometria de raios-X, utilizandose um difratômetro SHIMADZU XRD 6000, a uma velocidade de varredura de um grau por minuto [12]. O material apresentou-se altamente cristalino, com bandas típicas para o NiO e YSZ. Entretanto as bandas de $\mathrm{CoO}$ estavam ausentes dos espectros, apesar da intensa cor azul-cobalto da amostra, sugerindo que o cobalto se dispersou finamente sobre YSZ, sem a formação de cristalitos.

\subsection{Caracterização do Catalisador}

\subsubsection{Fluorescência de Raios X (XRF)}

A composição química dos catalisadores foi determinada por fluorescência de raios-X (XRF). A amostra para análise foi preparada pela mistura mecânica de $100 \mathrm{mg}$ de catalisador com $150 \mathrm{mg}$ de ácido bórico. A mistura foi então prensada em um molde a $150 \mathrm{kgf} / \mathrm{cm}^{2}$, formando uma pastilha sólida; foi utilizado um aparelho XRF 1800 da SHIMADZU ${ }^{\circledR}$.

\subsubsection{Espectroscopia Foto-eletrônica de Raios X (XPS)}

A análises de espectroscopia foto-eletrônica de raios X (XPS) foi executada com um aparelho Spectrometer ESCALAB NK2 ${ }^{\circledR}$, equipado com um ânodo duplo de $\mathrm{Mg} / \mathrm{Al}$. O espectro foi obtido por excitação da amostra por uma fonte de $\mathrm{Al} \mathrm{K} \alpha(1486,6 \mathrm{eV})$ operada a $14 \mathrm{kV}$ e $15 \mathrm{~mA}$, sob uma pressão de $10^{-8}$ mbar. O espectro de calibração foi o $\mathrm{C} 1 \mathrm{~s}$ a $285 \mathrm{eV}$. A amostra foi utilizada na forma de pó do catalisador após calcinação.

\subsubsection{Avaliação Catalítica}

O catalisador CATAC foi testado na reação de reforma a vapor do metano, entre 500 e $800^{\circ} \mathrm{C}$. Os testes foram executados em um micro-reator de quartzo de leito fixo e fluxo contínuo. Inicialmente $200 \mathrm{mg}$ de catalisador foram reduzidos in situ com uma mistura molar $10 \% \mathrm{H}_{2} / \mathrm{N}_{2}$ entre 30 e $850^{\circ} \mathrm{C}$ com taxa de aquecimento de $10^{\circ} \mathrm{C}$ por minuto, permanecendo em $850^{\circ} \mathrm{C}$ durante uma hora. Uma mistura $30 \%$ molar $\mathrm{CH}_{4} / \mathrm{N}_{2}$ foi introduzida no reator usando um misturador de gases; a vazão da mistura foi ajustada para $60 \mathrm{~mL}$ por minuto $(\mathrm{ml} / \mathrm{min})$ usando um medidor de fluxo do tipo bolhômetro. O vapor de água foi adicionado através de um saturador com temperatura controlada $\left(50^{\circ} \mathrm{C}\right)$, onde o vapor era arrastado pelo nitrogênio. Os produtos da reação foram analisados por cromatografia gasosa, utilizando uma coluna Carboxen ${ }^{B} 1010$ e detector de condutividade térmica (TCD) em série com um detector de ionização por chama (FID).

\subsection{Preparação da Célula Unitária}

O ânodo foi preparado com 2,5 g do catalisador CATAC, acrescido de $0,7 \mathrm{~g}$ de grafite Synth e o eletrólito foi uma fina camada de $0,7 \mathrm{~g}$ de YSZ puro. Enquanto, o cátodo foi uma camada porosa com $0,4 \mathrm{~g}$ de LSM na forma cristalina de perovskita (NexTech), acrescida de $0,15 \mathrm{~g}$ de grafite. A porosidade do ânodo e cátodo foi obtida pela adição da grafite, finamente pulverizada. Todas as camadas do conjunto ânodo/eletrólito/cátodo foram dispostas alternadamente em um molde de aço (diâmetro de $1,3 \mathrm{~cm}$ ) e prensado a $165 \mathrm{kgf} / \mathrm{cm} 2$; em seguida, a estrutura pastilhada foi sinterizada a $1380^{\circ} \mathrm{C}$ durante cinco horas, com rampas de aquecimento e resfriamento. Para evitar dilatação diferencial entre as duas camadas, produzindo trincas, a estrutura foi mantida dentro de um anel de alumina durante a sinterização.

A técnica de fabricação de camadas porosas e densas por prensagem, seguida de sinterização, tem cada vez mais despertado o interesse da comunidade científica [14-34]. A prensagem a seco reduz significantemente os custos de fabricação das membranas cerâmicas densas e porosas. Comparada com outros métodos de fabricação, a prensagem a seco é simples, reprodutível e eficiente em termos de custo. Entre os métodos de fabricação mais empregados, cita-se spray pirólise [35-52], screen printing [53, 54] e a 
deposição a vapor, física (PVD) ou química (CVD) [55], ou ainda uma combinação desses métodos [ㄷ6]. Muitos trabalhos preparam uma camada por prensagem e a segunda camada por screen printing; por exemplo, eletrólito [27, 31, 35], eletrólito e catodo [32], ou eletrodos [33] por prensagem e as demais camadas por outras técnicas.

Após sinterização, o material sintetizado neste trabalho apresentou contração linear de $40 \%$ e porosidade de $20 \%$. A contração do material foi determinada medindo-se o diâmetro e espessura da pastilha antes e após sinterização; a medida foi executada por meio de um micrômetro Mutitoyo Digital MDC-Lite. A porosidade, tendo em vista o grande tamanho dos poros, foi medida por um método bastante simples mas eficiente, amplamente usado na literatura [14-18]. A pastilha foi inicialmente pesada, em seguida imersa em água destilada e seca superficialmente, utilizando tecido com absorção intermediária (tipo perfex). Após essa etapa, a pastilha foi novamente pesada e a diferença de peso atribuída à água retida nos poros. Métodos mais complexos para a medida de porosidade são referidos na literatura, como massa específica do material [19],

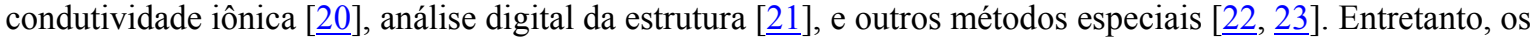
resultados dessas técnicas mais elaboradas não mostram nenhuma vantagem sobre o método da absorção de água ou solvente.

As telas de platina foram fixadas ao ânodo e ao cátodo da célula unitária utilizando-se tinta de platina (Heraeus, CL11-5349), para melhorar a condução elétrica da interface, e cola cerâmica de alta temperatura, para melhorar a resistência mecânica da adesão. A cola cerâmica foi fornecida pela Aremco Product, Inc., sendo uma mistura de cerâmica aderente em pó (571-L) e um líquido ativador (Ceramabond 571-L); essa cola apresenta alta resistência mecânica e dielétrica, bem como excelente resistência química. Após a fixação dos condutores de corrente com a tinta de platina, o conjunto foi termicamente tratado a $1100^{\circ} \mathrm{C}$ por uma hora. A Figura 1 mostra o esquema de preparação e componentes da célula unitária.

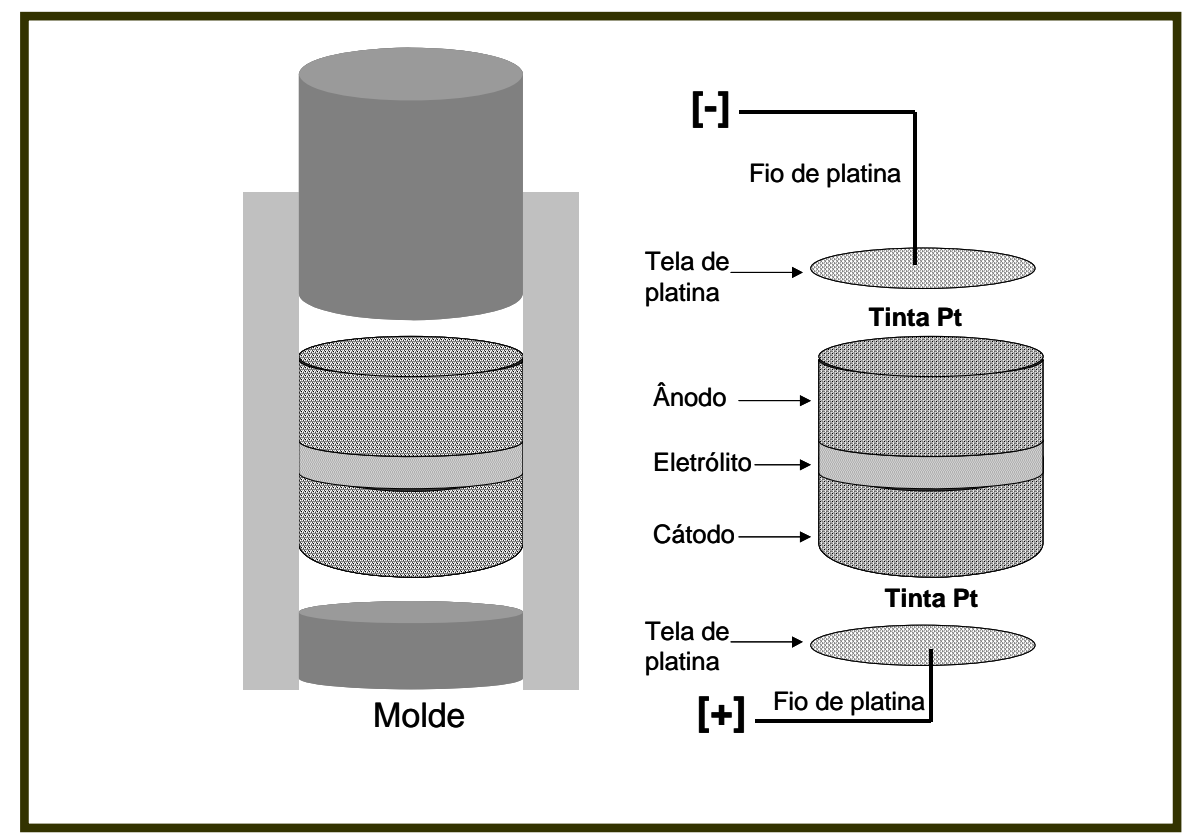

Figura 1: Esquema de prensagem e componentes da célula unitária.

\subsection{Avaliação da Célula Unitária}

A célula unitária foi fixada em um reator tubular concêntrico, confeccionado em alumina; o combustível foi alimentado pelo tubo interno. Enquanto, o circuito elétrico foi fechado por fios de platina. $\mathrm{O}$ $\mathrm{NiO}$ e o $\mathrm{CoO}$, incorporados ao ânodo, foram reduzidos in situ a $950^{\circ} \mathrm{C}$ com o combustível $\left(10 \%\right.$ molar de $\mathrm{H}_{2}$ em He). A célula unitária foi operada a várias temperaturas, a 1 bar e $1 \mathrm{~mL} / \mathrm{s} \mathrm{de} \mathrm{combustível.} \mathrm{Para} \mathrm{os} \mathrm{teste} \mathrm{de}$ desempenho da célula foram utilizados como combustíveis o hidrogênio e o metano, adicionados ao sistema diluídos em um gás inerte $\left(\mathrm{N}_{2}\right)$. Os testes com metano foram executados na presença de vapor d'água, que foi adicionada ao sistema através de um saturado mantido a $50^{\circ} \mathrm{C}$. As medidas de corrente e voltagem foram feitas a 800,850 e $950^{\circ} \mathrm{C}$, variando-se a resistência do circuito. 


\section{RESULTADOS E DISCUSSÃO}

A tabela 1 mostra os resultados da análise de XRF do catalisador CATAC e a composição esperada (nominal), esta determinada por cálculo estequiométrico, bem como as diferenças entre estes dois valores. A composição do níquel foi inferior à composição esperada, provavelmente devido à sua perda durante os processos de calcinação e sinterização. Em trabalhos anteriores [ㄷ6-60] foi observado que o níquel reage ativamente com óxidos metálicos a alta temperatura; neste trabalho, todos os processos de tratamento térmico foram conduzidos em suportes de alumina. Fenômeno similar deve ter ocorrido com o cobalto, o qual migrou da amostra durante os tratamentos térmicos; entretanto, como a concentração de níquel na amostra era muito superior, a perda de cobalto foi comparativamente menor.

Tabela 1: Composição química do catalisador determinada por XRF

\begin{tabular}{|l|c|c|c|}
\hline \multirow{2}{*}{ Analito } & XRF & Nominal & Diferença \\
\cline { 2 - 4 } & \multicolumn{3}{|c|}{ \% massa } \\
\hline $\mathbf{Z r O}_{2}$ & 56,1 & 56,0 & 0,1 \\
\hline $\mathbf{Y}_{\mathbf{2}} \mathbf{O}_{3}$ & 10,4 & $9,0 *$ & 1,4 \\
\hline $\mathbf{N i}$ & 29,5 & 32 & $-2,5$ \\
\hline $\mathbf{C o}$ & 3,9 & 3 & 0,9 \\
\hline
\end{tabular}

*valor obtido pela composição do YSZ indicado pelo fornecedor

A Figura 2 mostra o espectro de XPS para o CATAC calcinado. O níquel apresenta os dois estados de transição característicos (Ni 2p3/2 e Ni 2p1/2) na região de 875 e $855 \mathrm{eV}$, compatível à energia de ligação do $\mathrm{NiO}$ [61]. O cobalto por outro lado apresenta uma única banda de baixa energia de ligação, característica da espécie $\mathrm{Co}^{2+}$ [62]. Não há evidências de interação eletrônica entre as espécies superficiais dos dois metais, apesar do efeito sinergético do cobalto na atividade catalítica do níquel.

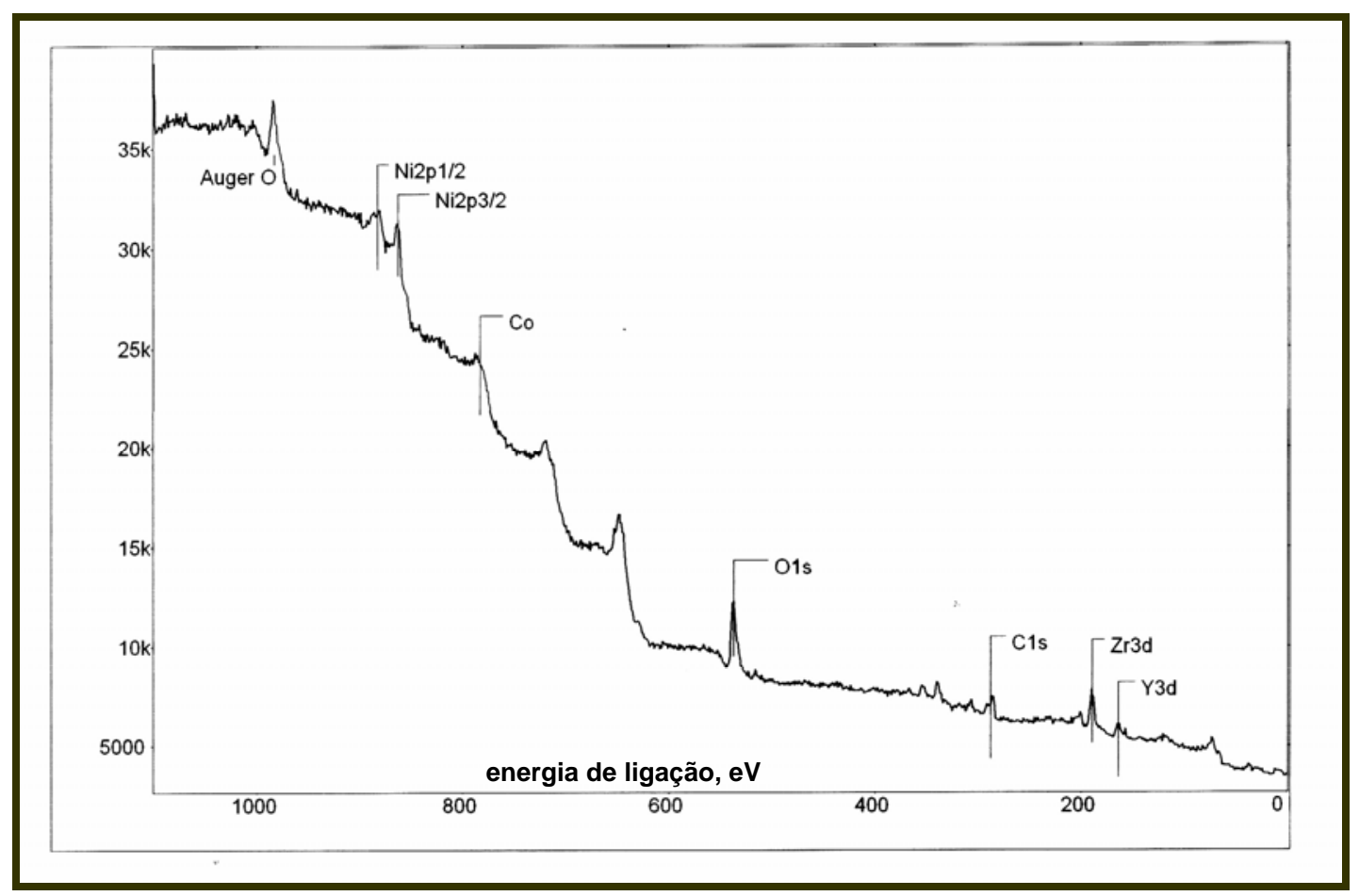

Figura 2: Análise por XPS do CATAC

Após os testes de desempenho da célula unitária, foram feitas micrografias dos componentes da célula utilizando um microscópio eletrônico de varredura (MEV); as Figuras 3 a 5 apresentam os resultados 
deste teste. A estrutura ânodo/eletrólito/cátodo foi fraturado transversalmente em vários pontos, com o auxílio de ferramentas de corte manual, tendo-se o cuidado de não contaminar ou danificar a face exposta. Os espécimes foram fixados em fita dupla-face de carbono e em seguida submetidos a revestimento de ouro em plasma a vácuo. O ânodo (Figura $3 \mathrm{~A}$ ) apresenta uma configuração porosa, uniformemente distribuída em toda a estrutura do material. O suporte (YSZ) está aparentemente cristalizado na forma cúbica, sobre o qual se depositam os cristalitos de níquel sem forma definida à ampliação de 1200 vezes (Figura $3 \mathrm{~B}$ ). A camada eletrolítica é densa (Figuras 4 A e B), virtualmente sem a presença de poros. A estrutura aparentemente apresenta uns poucos canais paralelos às interfaces, portanto sem conseqüências danosas ao desempenho da célula. A micrografia a maior ampliação (Figura 4 B) sugere uma cristalização na forma cúbica, benéfica à condutividade iônica do material; além disso, não há descontinuidade entre os cristais. A Figura 5 A apresenta a boa aderência entre as camadas de eletrólito e cátodo, sugerindo adequação do método de prensagem e sinterização. A Figura $5 \mathrm{~B}$, por sua vez, apresenta a estrutura porosa do cátodo recoberta com tinta de platina em vasta extensão de sua superfície; a tinta mostra um grande número de orifícios que permitiriam o acesso dos gases aos poros dos eletrodos.

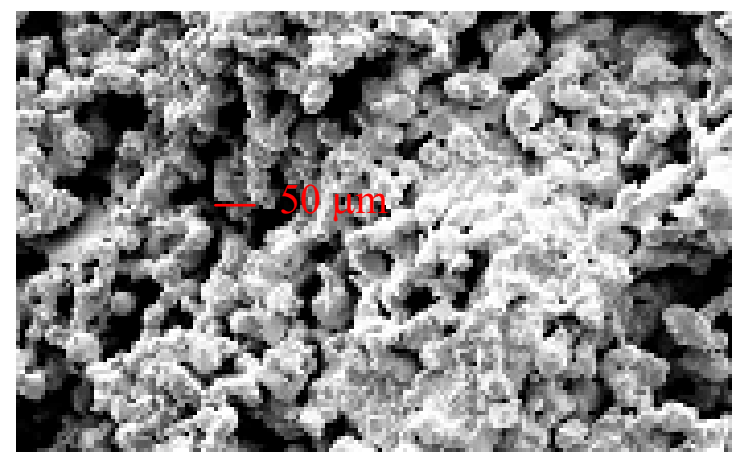

A

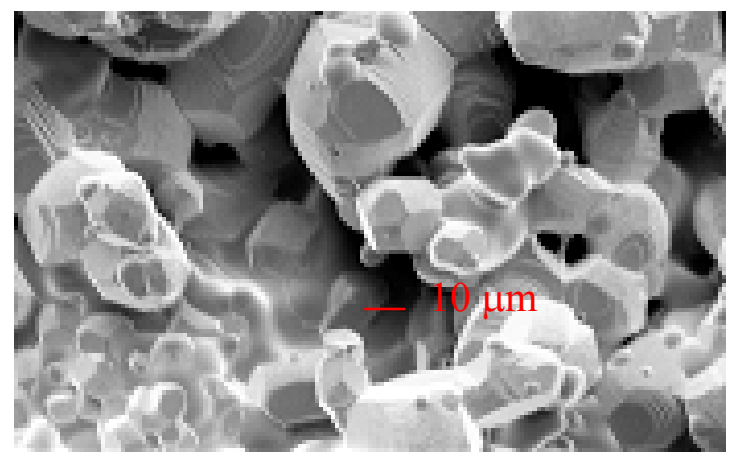

$\mathbf{B}$

Figura 3: MEV da fratura do ânodo a diferentes ampliações (A, 270 vezes; B, 1200 vezes)

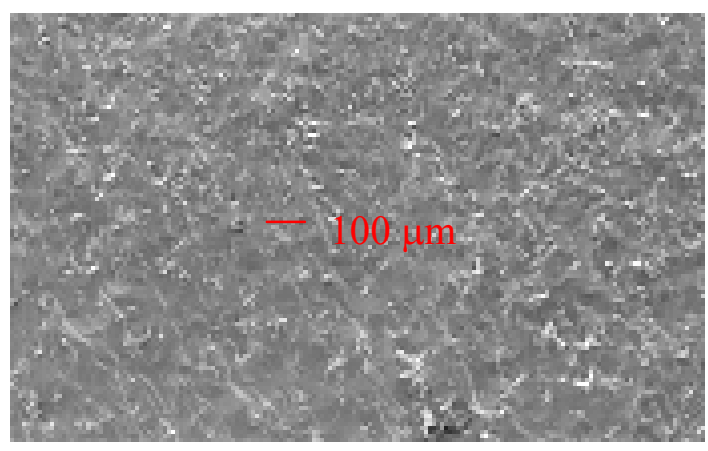

A

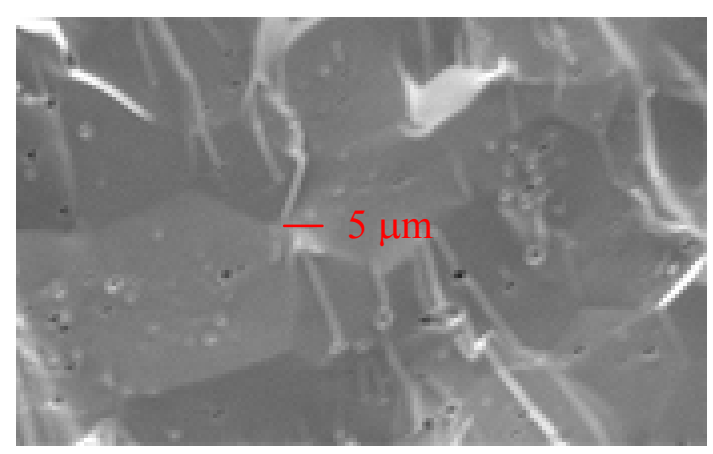

B

Figura 4: MEV da fratura do eletrólito a diferentes ampliações (A, 180 vezes; B, 2700 vezes). 


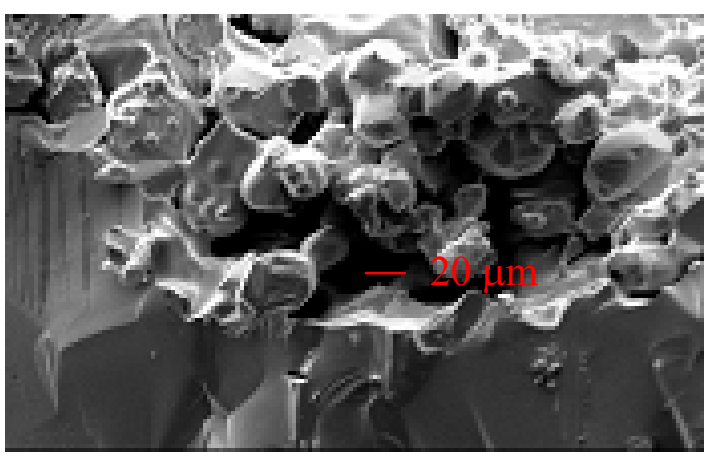

A

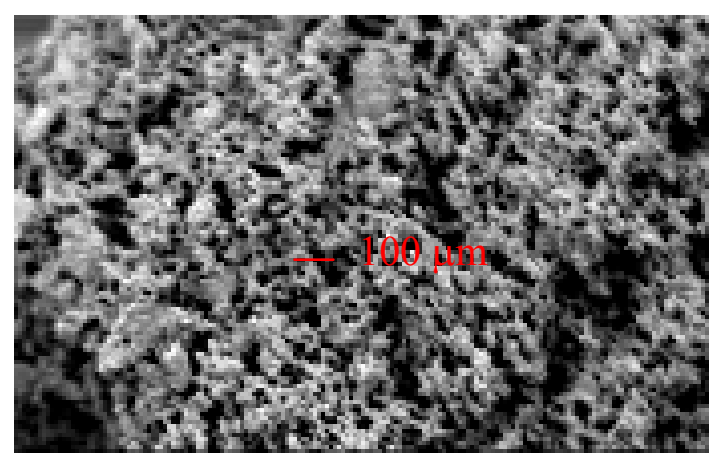

$\mathbf{B}$

Figura 5: MEV da fratura da interface do eletrólito e cátodo (A, ampliação de 700 vezes) e cátodo (B, ampliação de 100 vezes).

A Figura 6 apresenta os resultados da reforma a vapor do metano entre 500 e $800^{\circ} \mathrm{C}$. As reações de reforma do metano e etanol são apresentadas a seguir:

$$
\begin{array}{ll}
\text { Reforma do Metano: } & \mathrm{CH} 4(\mathrm{~g})+\mathrm{H} 2 \mathrm{O}(\mathrm{g}) \rightarrow \mathrm{CO}(\mathrm{g})+3 \mathrm{H} 2(\mathrm{~g}) \\
\text { Reforma do Etanol: } & \mathrm{C} 2 \mathrm{H} 3 \mathrm{OH}(\mathrm{g})+\mathrm{H} 2 \mathrm{O}(\mathrm{g}) \rightarrow 2 \mathrm{CO}(\mathrm{g})+3 \mathrm{H} 2(\mathrm{~g})
\end{array}
$$

$$
\text { Reação de Water Gas Shift: } \quad \mathrm{CO}(\mathrm{g})+\mathrm{H} 2 \mathrm{O}(\mathrm{g}) \rightarrow \mathrm{CO} 2(\mathrm{~g})+\mathrm{H} 2(\mathrm{~g})
$$

As reações de reforma ocorrem a alta temperatura (acima de $800^{\circ} \mathrm{C}$ ) em presença de um catalisador a base de metais de transição (níquel para o metano e níquel ou cobalto para o etanol). A essa elevada temperatura a reação de water gas shift é uma reação rápida, encontrado-se praticamente no equilíbrio, mas fortemente deslocada para a presença de reagentes [63]. A conversão do metano aumenta com o aumento da temperatura, mostrando um patamar em torno de $650^{\circ} \mathrm{C}$; surpreendentemente essa é faixa de temperatura na qual a produção de hidrogênio apresenta maior aumento. A Figura 6 também mostra a formação de hidrogênio e monóxido de carbono em função da temperatura. Os perfis das curvas de formação de $\mathrm{CO}$ e $\mathrm{H} 2$ apresentam comportamento semelhante, com máximos de formação em torno $720^{\circ} \mathrm{C}$. Este comportamento pode indicar a desativação do catalisador, devido à deposição de carbono, em temperaturas mais elevadas. A deposição de carbono foi estudada para catalisadores anôdicos, isto é, com teores de níquel da ordem de $35 \%$ em massa, na reforma a vapor do metano [64] e do etanol [63]. Na reforma do metano a deposição de carbono foi praticamente independente da concentração de vapor de água, até uma relação molar de $3: 1$; em qualquer caso, a deposição do carbono ocorreu principalmente nos primeiros quinze minutos da reação. A reforma de etanol apresentou produção intensa de carbono, para razões molares de água para etanol inferior a 3; aparentemente, a deposição de carbono não afetou significativamente a atividade do catalisador para a reforma do etanol. As caracterizações conduzidas neste e em outros trabalhos do grupo [65] não indicaram a presença de carbono na célula, quer seja visualmente, por análise termogravimétrica ou por microscopia eletrônica. Gorte e colabores [66] observaram que a atividade de uma célula a combustível foi reduzida a um terço da atividade original após vinte horas de operação, com uma mistura de decano e tolueno; essa queda do desempenho foi atribuída à deposição de carbono. 


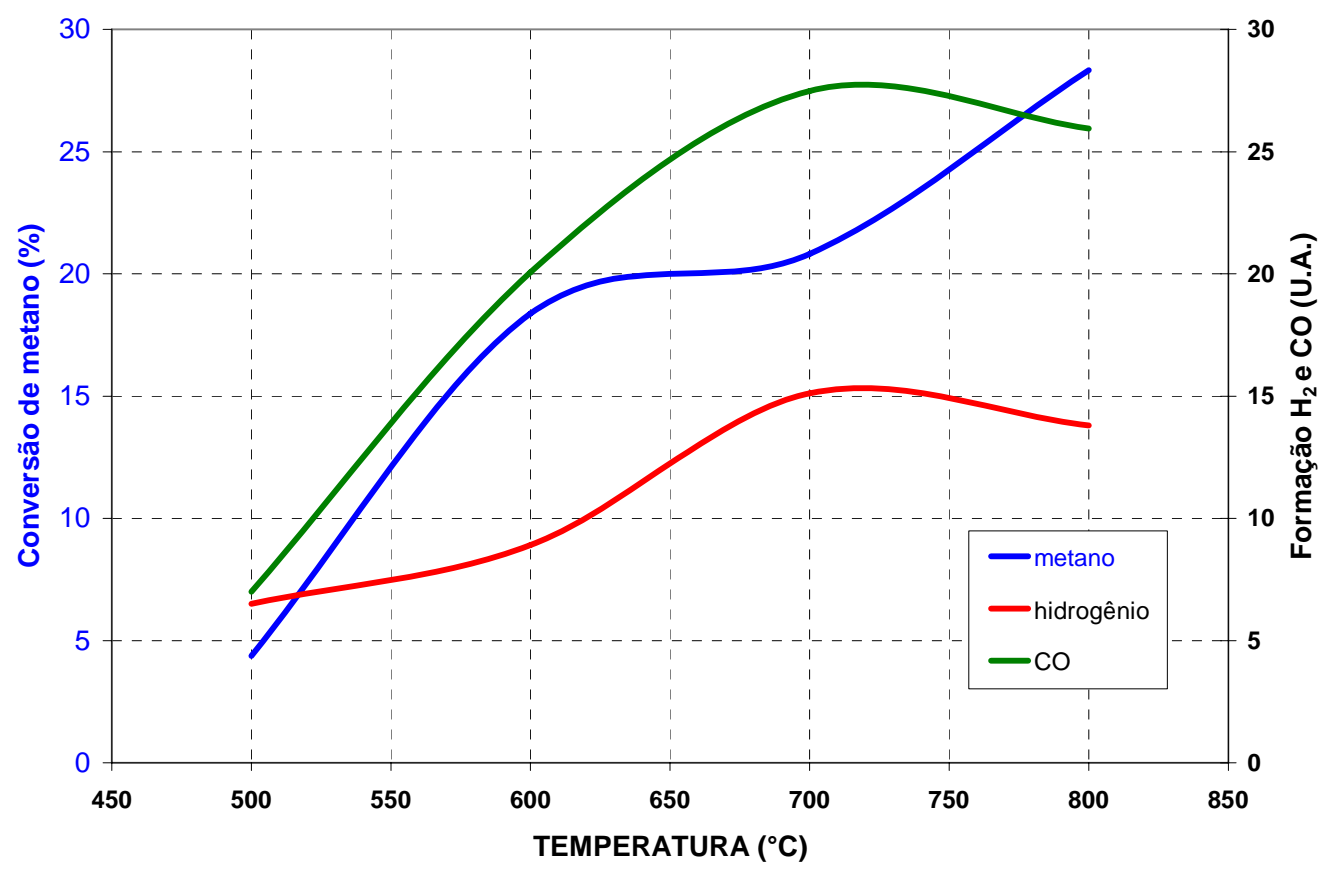

Figura 6: Conversão do metano, formação de $\mathrm{H}_{2}$ e $\mathrm{CO}$, em função da temperatura sobre CATAC.

A célula unitária foi testada a três temperaturas, utilizando metano ou hidrogênio como combustível, ambos diluídos a $50 \%$ molar em nitrogênio. A vazão de alimentação total foi mantida em torno de $2 \mathrm{~mL} / \mathrm{s}$, a pressão atmosférica. A Figura 7 apresenta as curvas de desempenho do dispositivo (tensão e densidade de potência versus densidade de corrente); a área útil da célula foi aproximadamente equivalente à área do tubo de alimentação de combustível (tubo interno do reator), igual a $0,3 \mathrm{~cm}^{2}$. A tensão variou inversamente proporcional com a corrente a 900 e $850^{\circ} \mathrm{C}$, utilizando hidrogênio como combustível; os coeficientes angulares foram -5,63 e -10,91 $\left(\mathrm{J} \mathrm{cm}^{2} \mathrm{~A}^{-1}\right)$ para 900 e $850^{\circ} \mathrm{C}$, respectivamente; o grau de correlação $\left(\mathrm{R}^{2}\right)$ para as curvas a $900 \mathrm{e} 850^{\circ} \mathrm{C}$ foi, respectivamente, 0,9951 e 0,9908 . Este resultado sugere, à primeira vista, que a reação eletroquímica da célula, nessas condições, é uma reação de primeira ordem e cineticamente irreversível. A $800^{\circ} \mathrm{C}$ para o metano como combustível, a tensão foi constante a partir de uma corrente de 5 $\mathrm{mA}$, não sendo possível a coleta de dados entre esta corrente e dados de circuito aberto. Essa célula de PaCOS unitária mostrou desempenho para a produção de energia elétrica comparativo a dados reportados na literatura [67]. Além disto, o gráfico de potência apresenta uma estimativa preliminar para o desempenho da célula utilizando hidrogênio e operando a $800^{\circ} \mathrm{C}$. Essa estimativa foi conduzida a partir da relação de Arrhenius, seguindo uma generalização utilizada por alguns autores [35, 68]. Grosso modo, pode-se inferir que a atividade da célula não dependente significativamente do combustível utilizado, seja hidrogênio ou metano. 


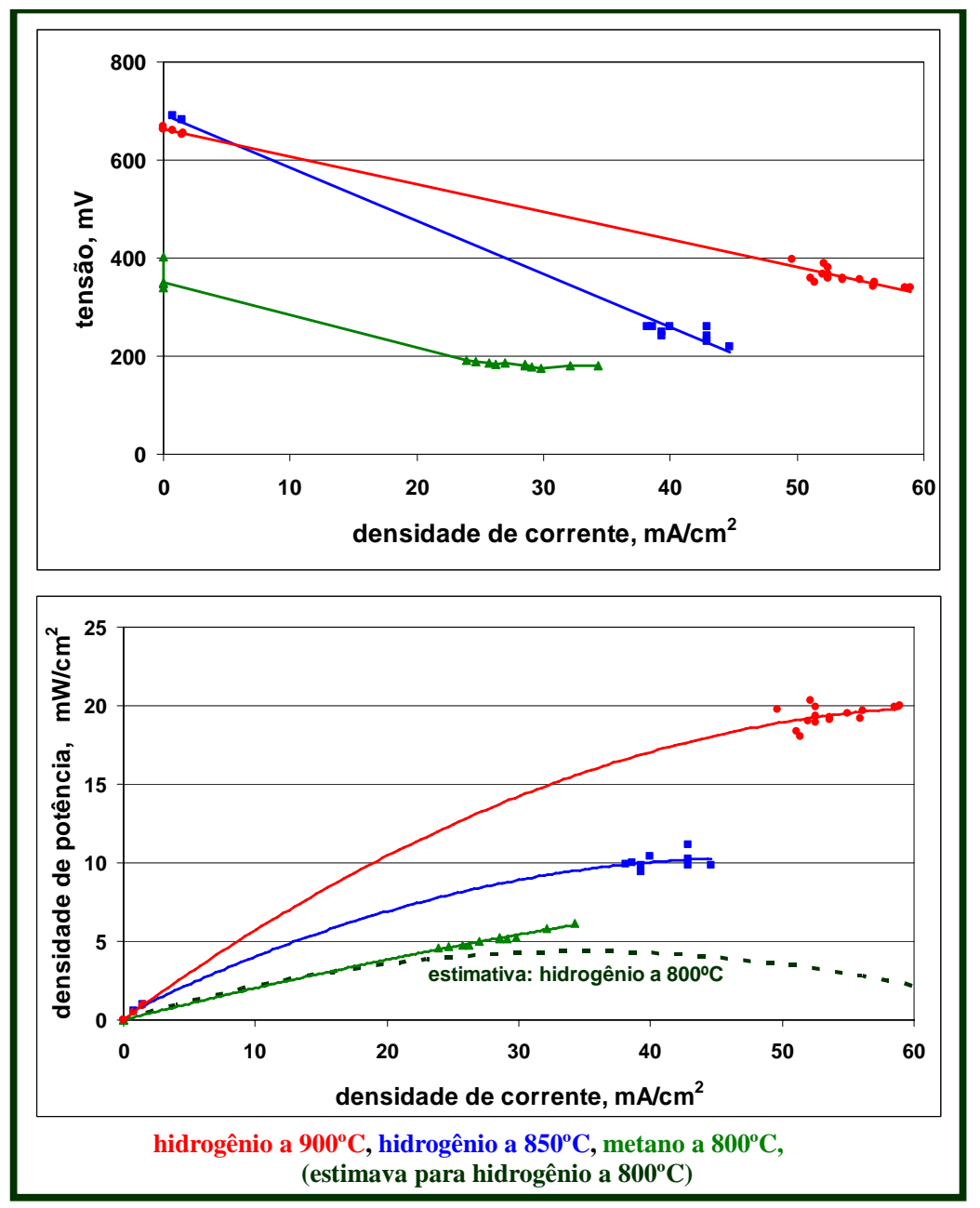

Figura 7: Curvas de desempenho para a célula do tipo PACOS unitária desenvolvido neste trabalho.

\section{CONCLUSÕES}

O catalisador final apresenta composição próxima à esperada, com uma pequena perda dos componentes metálicos durante a etapa de preparação. Além disso, o precursor calcinado apresenta as energias de ligação característicos de espécies do níquel e cobalto, sugerindo não haver interação eletrônica entre esses metais.

O eletro-catalisador a base de níquel e cobalto, suportados em YSZ, apresentou elevada atividade para a produção de hidrogênio pela reforma do metano, a baixas concentrações de vapor de água e baixas temperaturas (a partir de $500^{\circ} \mathrm{C}$ ). A formação de carbono é relativamente pequena, mas afeta a atividade do catalisador.

A célula unitária, preparada a partir do cermet desenvolvido neste trabalho, apresentou interfaces bem construídas e elevada porosidade dos eletrodos, em torno de $20 \%$ e distribuição uniforme dos poros. O eletrólito por sua vez apresentou elevada densificação e bom aspecto cristalino, mesmo após os testes executados a altas temperaturas. O dispositivo apresentou bom desempenho para a produção de energia elétrica a partir do metano.

\section{AGRADECIMENTOS}

Os autores agradecem à Rede Cooperativa Pilha a Combustível de Óxido Sólido (PACOS), ao CTPETRO/FINEP/CNPq, à Rede Cooperativa Norte/Nordeste de Catálise (RECAT) e à PETROBRAS. Os autores também agradecem ao Sr. Pascal Bargiela pela análise de XPS e à Sra. Célia C. Souza pelas análises de XRF. 
[1] MINH, N.Q., "Ceramic Fuel Cells", Journal of the American Ceramic Society, v. 76, pp. 563, 1993.

[2] SINGHAL, S.C., "Science and Technology of Solid-Oxide Fuel Cells", MRS Bulletin, v. 25, pp. 16, 2000.

[3] PETRUZZI, L., COCCHI, S., FINESCHI, F., "A Global thermo-electrochemical Model for SOFC Systems Design and Engineering”, Journal of Power Sources, v. 118, pp. 96, 2003.

[4] BARATTO, F., DIWEKAR, U.M., "Multi-objective trade-offs for Fuel cell-based Auxiliary Power Units: Case Study of South California Air Basin”, Journal of Power Sources, v. 139, pp. 197, 2005.

[5] LU, N., LI, Q., SUN, X., KHALEEL, M.A., "The Modeling of a Standalone solid-oxide Fuel Cell Auxiliary Power Unit", Journal of Power Sources, v. 161, n. 938, 2006.

[6] EG\&G TECHNICAL SERVICES, INC., "Fuel Cell Handbook (Seventh Edition)", U.S. Department of Energy, Morgantown, WV, 2004

[7] RINGUEDÉ, A., LABRINCHA, J.A., FRADE, J.R., "A Combustion Synthesis Method to Obtain Alternative Cermet Materials for SOFC Anodes", Solid State Ionics, v. 549, 2001.

[8] WANG, J.T., SAVINELL, R.F., WAMRIGHT, J., LTT, M., YU, H., "A $\mathrm{H}_{2} / \mathrm{O}_{2}$ Fuel Cell Using Acid Doped Polybenzimidazole as Polymer Electrolyte", Electrochimica Acta, v. 41, pp. 193, 1996.

[9] MORI, M., YAMAMOTO, T., ITOH, H., INABA, H., TAGAWA, H., "Proceedings of the Fifth International Symposium on Solid Oxide Fuel Cells (SOFC-V)", In: U. STIMMING, S.C. SINGHAL, H. TAGAWA, W. LEHNERT (Eds.), Aachen, Germany, pp. 869, 2-5 June 1997.

[10] RINGUEDÉ, A., BRONINE, D., FRADE, J.R., "Ni ${ }_{1-x} \mathrm{Co}_{\mathrm{x}} / \mathrm{YSZ}$ Cermet Anodes for Solid Oxide Fuel Cells", Electrochimica Acta, v. 48, pp. 437, 2002.

[11] LAGUNA-BERCERO, M.A., LARREA, A., PEÑA, J.I., MERINO, R.I., ORERA, V.M., "Structured Porous Ni- and Co-YSZ Cermets Fabricated from Directionally Solidified Eutectic Composites", Journal of the European Ceramic Society, v. 25, pp. 1455, 2005.

[12] CERQUEIRA, C.P., ALENCAR, M.G., SILVA, M.A., FIÚZA, R.P., SANTOS, J.L., BOAVENTURA, J.S., "Desenvolvimento de Protótipo de SOFC: Atividade do eletro-catalisador e Desempenho da Célula", In Anais do $13^{\circ}$ Congresso Brasileiro de Catálise, Foz de Iguaçu, Brasil, pp. 117, setembro, 2005.

[13] SILVA, M.A., CERQUEIRA, C.P., ALENCAR, M.G., SOUZA, D.R., BOAVENTURA, J.S., "Desenvolvimento de SOFC a Etanol: Estudo da Reforma do Etanol e Desempenho da Célula", In: Anais do $13^{\circ}$ Congresso Brasileiro de Catálise, Foz de Iguaçu, Brasil, pp. 123, Setembro, 2005.

[14] PRATIHAR, S.K., DAS SHARMA, A., MAITI, H.S., "Electrical Behavior of Nickel Coated YSZ Cermet Prepared by Electroless Coating Technique", Materials Chemistry and Physics, v. 96, pp. 388, 2006.

[15] JI, Y., LI, J., HE, T., WANG, J., SU, W., "The Effect of Pr co-dopant on the Performance of Solid Oxide Fuel Cells with Sm-doped Ceria Electrolyte", Journal of Alloys and Compounds, v. 389, pp. $317,2005$.

[16] KUMAR, M., KULANDAINATHAN, M.A., RAJ, I.A., CHANDRASEKARAN, R., PATTABIRAMAN, R., "Electrical and Sintering Behaviour of $\mathrm{Y}_{2} \mathrm{Zr}_{2} \mathrm{O}_{7}(\mathrm{YZ})$ pyrochlore-based Materials - The Influence of Bismuth", Materials Chemistry and Physics, v. 92, pp. 295, 2005.

[17] AN, S., LUA, C., WORRELLA, W.L., GORTEB, R.J., VOHS, J.M., "Characterization of $\mathrm{Cu}-\mathrm{CeO}_{2}$ Direct Hydrocarbon Anodes in a Solid Oxide Fuel Cell with Lanthanum Gallate Electrolyte", Solid State Ionics, v. 175, pp. 135, 2004. 
[18] KIM, H., DA ROSA, C., BOARO, M., VOHS, J.M., GORTE, R.J., "Fabrication of Highly Porous Yttria-Stabilized Zirconia by Acid Leaching Nickel from a Nickel-Yttria-Stabilized Zirconia Cermet", Journal of the American Ceramics Society, v. 85, pp. 1473, 2002.

[19] FU, C-Y., CHANG, C-L., HSU, C-S., HWANG, B-H., "Electrostatic Spray Deposition of $\mathrm{La}_{0.8} \mathrm{Sr}_{0.2} \mathrm{Co}_{0.2} \mathrm{Fe}_{0.8} \mathrm{O}_{3}$ Films", Materials Chemistry and Physics, v. 91, pp. 28, 2005.

[20] YAMAHARA, K., SHOLKLAPPERA, T.Z., JACOBSONA, C.P., VISCO, S.J., DE JONGHE, L.C., "Ionic Conductivity of Stabilized Zirconia Networks in Composite SOFC Electrodes", Solid State Ionics, v. 176, pp. 1359, 2005.

[21] SIMWONIS, D., TIETZ, F., STOVER, D., "Nickel Coarsening in Annealed Ni/8YSZ Anode Substrates for Solid Oxide Fuel Cells”, Solid State Ionics, v. 132, pp. 241, 2000.

[22] DIVISEK, J., WILKENHÖNER, R., VOLFKOVICH, Y., "Structure Investigations of SOFC Anode Cermets Part I: Porosity Investigations”, Journal of Applied Electrochemistry, v. 29, pp. 153, 1999.

[23] KUZNECOV, M., OTSCHIK, P., OBENAUS, P., EICHLER, K., SCHAFFRATH, W., "Diffusion Controlled Oxygen Transport and Stability at the perovskite/electrolyte Interface", Solid State Ionics, v. 157, pp. 371, 2003.

[24] WILL, J., MITTERDORFER, A., KLEINLOGEL, C., PEREDNIS, D., GAUCKLER, L.J., "Fabrication of Thin Electrolytes for second-generation Solid Oxide Fuel Cells", Solid State Ionics, v. 131, pp. 79,2000

[25] XIA, C., LIU, M., “A Simple and Cost-Effective Approach to Fabrication of Dense Ceramic Membranes on Porous Substrates", Journal of the American Ceramics Society, v. 84, pp. 1903, 2001.

[26] XIA, C., LIU, M., "Low-temperature SOFCs Based on $\mathrm{Gd}_{0.1} \mathrm{Ce}_{0.9} \mathrm{O}_{1.95}$ Fabricated by Dry Pressing", Solid State Ionics, v. 144, pp. 249, 2001.

[27] GE, X., HUANG, X., ZHANG, Y., LU, Z., XU, J., CHEN, K., DONG, D., LIU, Z., MIAO, J., SU, W., "Screen-printed Thin YSZ Films used as Electrolytes for Solid Oxide Fuel Cells", Journal of Power Sources, v. 159, pp. 1048, 2006.

[28] PANTEIX, P.J., JULIEN, I., BERNACHE-ASSOllANT, D., ABELARD, P., "Synthesis and Characterization of Oxide Ions Conductors with the Apatite Structure for Intermediate Temperature SOFC", Materials Chemistry and Physics, v. 95, pp. 313, 2006.

[29] XIE, Z., ZHU, W., ZHU, B., XIA, C., " $\mathrm{Fe}_{\mathrm{x}} \mathrm{Co}_{0.5-\mathrm{x}} \mathrm{Ni}_{0.5}-\mathrm{SDC}$ Anodes for low-temperature Solid Oxide Fuel Cells", Electrochimica Acta, v. 51, pp. 3052, 2006.

[30] SAHA, S., GHANAWAT, S.J., PUROHIT, R.D., "Solution Combustion Synthesis of Nano Particle $\mathrm{La}_{0.9} \mathrm{Sr}_{0.1} \mathrm{MnO}_{3}$ Powder by a Unique oxidant-fuel Combination and its Characterization", Journal of Material Science, v. 41, pp. 1939, 2006.

[31] XIN, X., LÜ, Z., HUANG, X., SHA, X., ZHANG, Y., CHEN, K., AI, N., ZHU, R., SU, W., "Solid Oxide Fuel Cells with Dense yttria-stabilized Zirconia Electrolyte Membranes Fabricated by a dry Pressing Process", Journal of Power Sources, v. 160, pp. 1221, 2006.

[32] VON DOLlEN, P., BARNETT, S., “A Study of Screen Printed Yttria-Stabilized Zirconia Layers for Solid Oxide Fuel Cells", Journal of the American Ceramic Society, v. 88, pp. 3361, 2005.

[33] ROTUREAU, D., VIRICELlE, J.-P., PIJOLAT, C., CAILlOL, N., PIJOLAT, M., "Development of a Planar SOFC Device Using screen-printing Technology", Journal of the European Ceramic Society, v. 25, pp. 2633, 2005. 
[34] SRDIC, V.V., OMORJAN, R.P., SEYDEL, J., "Electrochemical Performances of (La,Sr)CoO ${ }_{3}$ Cathode for zirconia-based Solid Oxide Fuel Cells", Materials Science and Engineering B, v. 116, pp. 119, 2005.

[35] LENG, Y.J., CHAN, S.H., KHOR, K.A., JIANG, S.P., "Performance Evaluation of anode-supported Solid Oxide Fuel Cells with Thin Film YSZ Electrolyte", International Journal of Hydrogen Energy, v. 29, pp. 1025, 2004.

[36] FUKUI, T., OHARA, S., NAITO, M., NOGI, K., "Performance and Stability of SOFC Anode Fabricated from NiO/YSZ Composite Particles", Journal of the European Ceramic Society, v. 23, pp. 2963, 2003.

[37] FAGG, D.P., MATHER, G.C., FRADE, J.R., "Cu-Ce ${ }_{0.8} \mathrm{Gd}_{0.2-\delta}$ Materials as SOFC Electrolyte and Anode", Ionics, v. 9, pp. 214, 2003.

[38] PEREDNIS, D., GAUCKLER, L.J., "Solid Oxide Fuel Cells with Electrolytes Prepared via Spray Pyrolysis", Solid State Ionics, v. 166, pp. 229, 2004.

[39] SUDA, S., ITAGAKI, M., NODE, E., TAKAHASHI, S., KAWANO, M., YOSHIDA, H., INAGAKI, T., "Preparation of SOFC Anode Composites by Spray Pyrolysis", Journal of the European Ceramic Society, v. 26, pp. 593, 2006.

[40] FUKUI, T., OHARA, S., NAITO, M., NOGI, K., "Performance and Stability of SOFC Anode Fabricated from NiO-YSZ Composite Particles”, Journal of Power Sources, v. 110, pp. 91, 2002.

[41] BOULC'H, F., DJURADO, E., “Structural Changes of rare-earth-doped, Nanostructured Zirconia Solid Solution", Solid State Ionics, v. 157, pp. 335, 2003.

[42] FUKUI, T., OHARA, S., NAITO, M., NOGI, K., "Performance and Stability of SOFC Anode Fabricated from NiO-YSZ Composite Particles", Journal of Chemical Engineering of Japan, v. 34, pp. 964, 2001.

[43] BECKEL, D., DUBACH, A., STUDART, A.R., GAUCKLER, L.J., "Spray Pyrolysis of $\mathrm{La}_{0.6} \mathrm{Sr}_{0.4} \mathrm{Co}_{0.2} \mathrm{Fe}_{0.8} \mathrm{O}_{3-\delta}$ Thin Film Cathodes”, Journal of Electroceramics, v. 16, pp. 221, 2006.

[44] ZHANG, X., ROBERTSON, M., DECÈS-PETIT, C., XIE, Y., HUI, R., YICK, S., STYLES, E., ROLlER, J., KESLER, O., MARIC, R., GHOSH, D., "NiO-YSZ Cermets Supported Low Temperature Solid Oxide Fuel Cells”, Journal of Power Sources, v. 161, pp. 301, 2006.

[45] STÖVER, D., D. HATHIRAMANI, R. VAßEN, R. J. DAMANI, "Plasma-sprayed components for SOFC applications”, Surface \& Coatings Technology, v. 201, pp. 2002, 2006.

[46] SNIJKERS, F., DE WILDE, A., MULLENS, S., LUYTEN, J., “Aqueous Tape Casting of Ytria Stabilised Zirconia Using Natural Product Binder", Journal of the European Ceramic Society, v. 24, pp. 1107, 2004.

[47] RADOVIC, M., LARA-CURZIO, E., "Mechanical Properties of Tape Cast nickel-based Anode Materials for Solid Oxide Fuel Cells Before and After Reduction in Hydrogen", Acta Materialia, v. 52, pp. 5747, 2004.

[48] JANG, W.S., HYUN, S.H., KIM, S.G., "Preparation of YSZ/YDC and YSZ/GDC Composite Electrolytes by the Tape Casting and sol-gel dip-drawing Coating Method for low-temperature SOFC", Journal of Materials Science, v. 37, pp. 2535, 2002.

[49] CLEMMER, R.M.C., CORBIN, S.F., "Influence of Porous Composite Microstructure on the Processing and Properties of Solid Oxide Fuel Cell Anodes”, Solid State Ionics, v. 166, pp.251, 2004.

[50] KAWANO, M., HASHINO, K., YOSHIDA, H., IJICHI, H., TAKAHASHI, S., SUDA, S., INAGAKI T., "Synthesis and Characterizations of Composite Particles for Solid Oxide Fuel Cell Anodes by 
Spray Pyrolysis and Intermediate Temperature Cell Performance", Journal of Power Sources, v. 152, 2005, pp. 196.

[51] IVANOV, V.V., A. LIPILIN, S., Y. KOTOV, A., KHRUSTOV, V.R., SHKERIN, S.N., PARANIN, S.N., SPIRIN, A.V., KAYGORODOV, A.S., "Formation of a thin-layer electrolyte for SOFC by Magnetic Pulse Compaction of Tapes Cast of Nanopowders", Journal of Power Sources, v. 159, pp. $605,2006$.

[52] MAFFEI, N., DE SILVEIRA, G., "Interfacial Layers in Tape Cast anode-supported Doped Lanthanum Gallate SOFC Elements”, Solid State Ionics, v. 159, pp. 209, 2003.

[53] KHARTON, V.V., TSIPISA, E.V., YAREMCHENKOA, A.A., FRADE, J.R., "Surface-limited Oxygen Transport and Electrode Properties of $\mathrm{La}_{2} \mathrm{Ni}_{0.8} \mathrm{Cu}_{0.2} \mathrm{O}_{4+\delta}$ ", Solid State Ionics, v. 166, pp. 327, 2004.

[54] SUDA, S., TAKAHASHI, S., KAWANO, M., YOSHIDA, H., INAGAKI, T., "Effects of Atomization Conditions on Morphology and SOFC Anode Performance of Spray Pyrolyzed NiO- $\mathrm{Sm}_{0.2} \mathrm{Ce}_{0.8} \mathrm{O}_{1.9}$ Composite Particles", Solid State Ionics, v. 177, pp. 1219, 2006.

[55] WANG, H.B., SONG, H.Z., XIA, C.R., PENG, D.K., MENG, G.Y., "Aerosol-assisted MOCVD Deposition of YDC Thin Films on (NiO + YDC) Substrates", Materials Research Bulletin, v. 35, pp. $2363,2000$.

[56] COMPSON, C., LIU, M., "Fabrication and Characterization of Hermetic Solid Oxide Fuel Cells Without Sealant", Solid State Ionics, v. 177, pp. 367, 2006.

[57] BOAVENTURA, J.S., AGUIAR, A.B., FRANK, M.H.T., CAMPOS, M.F., BRANDÃO, S.T., "Célula a Combustível: Novos Eletrocatalisadores para Ânodos de SOFC e Correlação entre Desempenho da Célula e Atividade Catalítica” In: Rio Oil \& Gas Expo and Conference, 2004.

[58] ALENCAR, M.G., SILVA, M.A., CERQUEIRA, C.P., AGUIAR, A.B., SANTOS, J.L, BOAVENTURA, J.S., "Protótipo de SOFC - UFBA: Desenvolvimento e Operação" In: V ENCAT, RECIFE, 2004.

[59] ROCHA, F.S., DIAS, F.L.S., PEIXOTO, F.S., AGUIAR, A.B., DA SILVA, M.A., BOAVENTURA, J.S., "Desenvolvimento de Célula a Combustível $(\mathrm{CaC})$ do tipo SOFC" In: XXV1 CLAQ/27 RASBQUIMICA, Salvador, 2004.

[60] SILVA, M.A., AGUIAR, A.B., DIAS, F.L.S., PEIXOTO, F.S., BOAVENTURA, J.S., "Síntese e Avaliação de Eletrocatalisadores para SOFC” In: XXV1 CLAQ/27 RASBQUIMICA, Salvador, 2004.

[61] VELU, S., SUZUKIA, K., VIJAYARAJ, M., BARMAN, S., GOPINATH, C.S., "In situ XPS investigations of $\mathrm{Cu}_{1-\mathrm{x}} \mathrm{Ni}_{\mathrm{x}} \mathrm{ZnAl}$-mixed Metal Oxide Catalysts used in the Oxidative Steam Reforming of bio-ethanol", Applied Catalysis B: Environmental, v. 55, pp. 287, 2005.

[62] MENG, M., ZHA, Y., LUO, J., HU, T., XIE, Y., LIU, T., ZHANG, J., “A Study on the Catalytic Synergy Effect Between Noble Metals and Cobalt Phases in Ce-Al-O Supported Catalysts", Applied Catalysis A: General, v. 301, pp.145, 2006.

[63] SILVA, M.A., BRANDÃO, S.T., BOAVENTURA, J.S., "Síntese e Caracterização de Catalisadores a base de Níquel e Cobalto para a Produção de Hidrogênio a partir do Etanol", In: Anais do XX SICAT-Simpósio Ibero-Americano de Catálise, Gramado, Brasil, 2006

[64] PEIXOTO, F.S., AGUIAR, A.B., BOAVENTURA, J.S., "Deposição de Coque em Catalisadores a Base de Níquel para Células a Combustível do tipo SOFC", In: Anais do XLIII Congresso Brasileiro de Química, Ouro Preto, 2003

[65] ROCHA, F.S., PEIXOTO, F.S., SOBRAL, A.S., MARQUES, I.S., BOAVENTURA, J.S., "Estudo Comparativo de Diferentes Suportes em Catalisadores a base de Ni para Células a Combustível”, In: Anais do XLIII Congresso Brasileiro de Química, Ouro Preto, 2003 
[66] KIM, T., LIU, G., BOARO, M., LEE, S.-I., VOHS, J.M., GORTE, R.J., AL-MADHI, O.H., DABBOUSI, B.O., "A Study of Carbon Formation and Prevention in hydrocarbon-fueled SOFC", Journal of Power Sources, v. 155, pp. 231, 2006.

[67] XIA, C., RAUCH, W., CHEN, F., LIU, M., " $\mathrm{Sm}_{0.5} \mathrm{Sr}_{0.5} \mathrm{CoO}_{3}$ Cathodes for low-temperature SOFCs", Solid State Ionics, v. 149, pp. 11, 2002.

[68] HOTZ, N., SENN, S.M., POULIKAKOS, D., "Exergy Analysis of a Solid Oxide Fuel Cell Micropowerplant", Journal of Power Sources, v. 158, pp. 333, 2006. 